\title{
Preparation of Cerium Orthophosphate Nanosphere by Coprecipitation Route and Its Structural, Thermal, Optical, and Electrical Characterization
}

\author{
Seema Verma and K. K. Bamzai \\ Crystal Growth and Material Research Laboratory, Department of Physics \& Electronics, University of Jammu, \\ Jammu 180006, India \\ Correspondence should be addressed to K. K. Bamzai; kkbamz@yahoo.com
}

Received 28 May 2014; Revised 8 August 2014; Accepted 22 August 2014; Published 16 September 2014

Academic Editor: Frank Hubenthal

Copyright (C) 2014 S. Verma and K. K. Bamzai. This is an open access article distributed under the Creative Commons Attribution License, which permits unrestricted use, distribution, and reproduction in any medium, provided the original work is properly cited.

\begin{abstract}
Cerium orthophosphate $\left(\mathrm{CePO}_{4}\right)$ nanoparticles were synthesized via wet chemical coprecipitation technique using cerium nitrate hexahydrate for $\mathrm{Ce}^{3+}$ ion and ammonium dihydrogen phosphate for $\mathrm{PO}_{4}{ }^{3-}$ ion source. X-ray diffraction (XRD) analysis suggests that the material belongs to monoclinic crystal system with crystallite size of $49.3 \mathrm{~nm}$. Scanning electron microscope (SEM) and transmission electron microscope (TEM) reveal the surface morphology of the prepared nanoparticles as nanospheres having grain size in the range of $30-50 \mathrm{~nm}$. The energy dispersive X-ray analysis (EDAX) gives elemental composition present in the grown nanomaterial. Thermogravimetric analysis suggests that the structural phase transition is above $800^{\circ} \mathrm{C}$. The optical properties include UV-VIS-NIR absorption and the photoluminescence spectrum shows the absorption and emission peaks in the ultraviolet region. The dielectric constant $\left(\varepsilon^{\prime}\right)$ and ac conductivity properties were investigated with regard to change in temperature (40 to $500^{\circ} \mathrm{C}$ ) and frequency $(5 \mathrm{kHz}$ to $1 \mathrm{MHz})$. The dielectric measurement indicates that the transition is diffused and the activation energy values decrease suggesting that the conduction mechanism is due to hopping of the charge carriers from one site to another.
\end{abstract}

\section{Introduction}

Rare earth elements (REEs) known as lithophile are the elements enriched in the earth crust which occur naturally because all are trivalent and form a special group of transition elements in the periodic table. Among these REEs, cerium $(\mathrm{Ce})$ is found in abundance which makes it one of the cheapest rare earth metals. However, cerium is found in several minerals like monazite (Ce, $\mathrm{La}, \mathrm{Nd}, \mathrm{Th}) \mathrm{PO}_{4}$, xenotime ( $\mathrm{Y}, \mathrm{Ce}) \mathrm{PO}_{4}$, bastnasite $(\mathrm{Ce}, \mathrm{La}) \mathrm{CO}_{3}(\mathrm{~F}, \mathrm{OH})$, and cerite $(\mathrm{Ce}, \mathrm{La})_{9}(\mathrm{Mg}, \mathrm{Fe}) \mathrm{Si}_{7}(\mathrm{O}, \mathrm{OH}, \mathrm{F})_{28}$. Orthophosphates are substances that are composed of isolated $\mathrm{PO}_{4}$ tetrahedra analogous to "orthosilicates." The most common naturally occurring orthophosphates are apatite $\left[\mathrm{Ca}_{3}\left(\mathrm{PO}_{4}\right)_{3} \mathrm{~F}, \mathrm{Cl}, \mathrm{OH}\right]$ and monazite $\left(\mathrm{LnPO}_{4}\right)$ where "Ln" refers to rare earth elements. Rare earth orthophosphates with the general formula $\mathrm{RXO}_{4}$ (where $\mathrm{R}=$ rare earth and $\mathrm{X}=\mathrm{P}, \mathrm{As}$, or $\mathrm{V}$ ) belong to a family that crystallizes in different structural types like hexagonal, tetragonal, and monoclinic depending on the radius of ions and temperature. The rare earths compounds with large ionic radii, namely, $\mathrm{RPO}_{4}$ with $\mathrm{R}=\mathrm{La}, \mathrm{Ce}, \mathrm{Pr}$, $\mathrm{Nd}, \mathrm{Sm}, \mathrm{Eu}$, and $\mathrm{Gd}$, crystallize in the monoclinic monazite structure, whereas rare earth compounds with small ionic radii, namely, $\mathrm{RPO}_{4}(\mathrm{R}=\mathrm{Sm}, \mathrm{Eu}, \mathrm{Gd}, \mathrm{Tb}, \mathrm{Dy}, \mathrm{Ho}, \mathrm{Er}, \mathrm{Tm}$, $\mathrm{Yb}, \mathrm{Lu}, \mathrm{Y}$, and $\mathrm{Sc}$ ), crystallize in the tetragonal zircon (or xenotime) structure [1]. The hexagonal structure is the low temperature phase and it can transform into the monoclinic structure, while the tetragonal maintains its structure after calcinations at $900^{\circ} \mathrm{C}[2-4]$.

Cerium orthophosphate $\left(\mathrm{CePO}_{4}\right)$ has attracted attention of many researchers because of its use in the area of fluorescence, catalytic materials, ceramic composite materials with high mechanical properties, and ion exchange [5-7]. $\mathrm{CePO}_{4}$ doped with different rare earth elements can be used in colour 


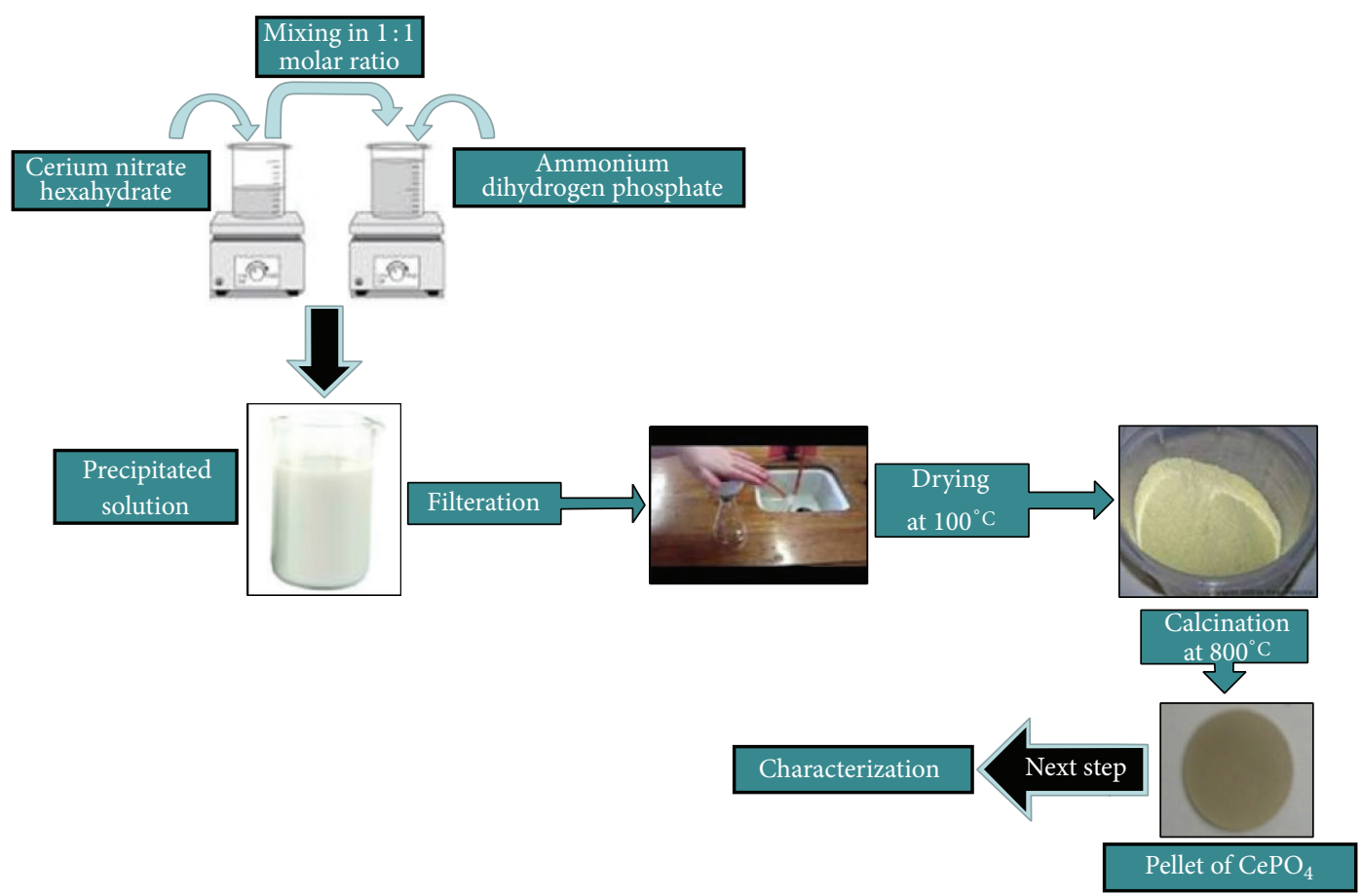

FIGURE 1: Schematic diagram for synthesis of cerium orthophosphate $\left(\mathrm{CePO}_{4}\right)$ via coprecipitation technique.

displays, field effect transistors, optoelectronics, medical and biological labels, solar cells, and light sources [8]. $\mathrm{CePO}_{4}$ nanotubes have become a simple and effective biosensing platform for the integration of heme proteins/enzymes and electrodes, which can provide analytical access to a large group of enzymes for a wide range of bioelectrochemical applications [9]. Bao et al. [10] reported low temperature hydrothermal synthesis and structure control of nanosized $\mathrm{CePO}_{4}$ whereas Lai et al. [11] reported UV luminescence property of $\mathrm{YPO}_{4}$ : $\mathrm{RE}\left(\mathrm{RE}=\mathrm{Ce}^{3+}, \mathrm{Tb}^{3+}\right)$ prepared by wet chemistry route. Synthesis of $\mathrm{CePO}_{4}$ : $\mathrm{Tb}$ nanoparticles was reported by liquid phase synthesis in high boiling coordinating solvents, whose structure is monazite [12]. Hexagonal and monoclinic $\mathrm{CePO}_{4}$ nanowires were prepared through hydrothermal reaction by Zhang and Guan [13]. The optical reflection spectrum of $\mathrm{CePO}_{4}$ is affected critically by their crystallization which in turn depends on the method of preparation and the calcination temperature $[14,15]$. Therefore, formation and structure of phosphate depend on rate and time of heating, the cooling rate of melt, the atmosphere, kind of cations of phosphate, and the ratio of phosphorous/cation [16]. As per the literature survey, cerium orthophosphate nanomaterials were synthesized by techniques which involve low basic $\mathrm{pH}$ value. However, the novelty of the present research work is the preparation of cerium orthophosphate nanoparticles by coprecipitation technique which is based on high $\mathrm{pH}$ value. Therefore, in the present investigation, the authors report the synthesis of monoclinic $\mathrm{CePO}_{4}$ nanospheres by simple coprecipitation method calcinated at $800^{\circ} \mathrm{C}$ for $2 \mathrm{hr}$ and then carried out its detailed characteristics viz-a-viz optical and electrical.

\section{Material and Methods}

2.1. Material Preparation. Cerium orthophosphate nanoparticles were prepared by coprecipitation method using cerium nitrate hexahydrate $\left(\mathrm{Ce}\left(\mathrm{NO}_{3}\right)_{3} \cdot 6 \mathrm{H}_{2} \mathrm{O}\right) \quad 99.9 \%$ pure (Alfa Aesar) and ammonium dihydrogen phosphate $\left(\mathrm{NH}_{4} \mathrm{H}_{2} \mathrm{PO}_{4}\right)$ 99.9\% pure (Alfa Aesar) as precursor. Figure 1 illustrates the schematic diagram for synthesis of cerium orthophosphate $\left(\mathrm{CePO}_{4}\right)$ via coprecipitation method. Cerium nitrate hexahydrate of 0.5 molarity $(\mathrm{M})$ was prepared in deionized water under stirring using a mechanical stirrer. Ammonium dihydrogen phosphate of the same molarity was added slowly to the cerium nitrate in the $1: 1$ molar ratio. Ammonium hydroxide $\left(\mathrm{NH}_{4} \mathrm{OH}\right)$ was added to the mixture drop by drop to adjust the $\mathrm{pH}$ value at 12 for the flocculation of the precipitate and then keeping it under vigorous stirring at $80^{\circ} \mathrm{C}$ for half an hour for complete precipitation. A milky white precipitate was obtained in the beaker and is allowed to settle down for $24 \mathrm{hr}$ at room temperature. These precipitates were then filtered and washed with distilled water and ethanol for several times to remove the nitrate ions. The milky white slurry of cerium orthophosphate thus obtained was dried, ground well in an agate mortar, and further calcinated in a furnace at $800^{\circ} \mathrm{C}$ for $2 \mathrm{hr}$ under air atmosphere. The following reaction is expected to take place leading to the formation of cerium orthophosphate $\left(\mathrm{CePO}_{4}\right)$ nanoparticles:

$$
\begin{gathered}
\mathrm{Ce}\left(\mathrm{NO}_{3}\right)_{3} \cdot 6 \mathrm{H}_{2} \mathrm{O}+\mathrm{NH}_{4} \mathrm{H}_{2} \mathrm{PO}_{4}+2 \mathrm{NH}_{4} \mathrm{OH} \\
\longrightarrow \mathrm{CePO}_{4}+3 \mathrm{NH}_{4} \mathrm{NO}_{3}+8 \mathrm{H}_{2} \mathrm{O} \uparrow
\end{gathered}
$$


2.2. Characterization. The cerium orthophosphate nanoparticles were characterized using various physicochemical techniques like X-ray diffraction analysis, particle size analyzer, transmission electron microscope, and scanning electron microscopy coupled with energy dispersive X-ray analysis (SEM-EDAX); optical properties include UV-VIS-NIR spectroscopy and photoluminescence spectrophotometer, and electrical properties include dielectric constant, dielectric loss, and conductivity. The phase identification was carried out by X-ray diffraction patterns using PAnalytical X'Pert Pro diffractometer with a $\mathrm{CuK} \alpha$ radiation $(\lambda=1.54060 \AA)$, the intensities of the diffraction beam were obtained in the $2 \theta$ range between $20^{\circ}$ and $70^{\circ}$. Debye-Scherer relation was used to determine the crystallite size. The particle size was measured with Zetasizer Nano ZS (Malvern Instruments Ltd., UK). In order to see the microstructure studies scanning electron microscope of JEOL Model JSM-6390 LV supplemented with energy dispersive X-rays analysis (EDAX) of model number JEOL JED-2300 was used. The size and shape of nanoparticles were observed under transmission electron microscope of Tecnai $\mathrm{G}^{2} 20 \mathrm{~S}$-Twin working at a $200 \mathrm{kV}$ accelerating voltage. Thermogravimetric analysis (TGA) and differential thermal analysis (DTA) curves were recorded simultaneously on the thermal analyzer (Shimadzu make DTG-60) over the temperature range from room temperature to $1000^{\circ} \mathrm{C}$ at the heating rate of $10^{\circ} \mathrm{C} / \mathrm{min}$ at a flow rate of $30 \mathrm{~mL} / \mathrm{min}$. Fourier transform infrared (FTIR) spectrum was obtained on IR Prestige-21 (Shimadzu) spectrophotometer in the region from 400 to $3500 \mathrm{~cm}^{-1}$ using $\mathrm{KBr}$ pellet. The optical absorption was measured in UV-VIS-NIR region with Varian Carry 5000 spectrophotometer. The photoluminescence (PL) was investigated by Perkin Elmer Luminescence LS50B at room temperature. The electrical characteristics which include behaviour of dielectric constant $\left(\varepsilon^{\prime}\right)$, dielectric loss $(\tan \delta)$ with frequency, and temperature were studied using automated impendence analyzer (LF 4192A model) interface with USB GPIB converter 82357 B (Agilent) and further automated by using a computer for data recording, storage, and analysis.

\section{Results and Discussion}

3.1. Structural Characterization. The phase, purity, and crystallinity of the prepared cerium orthophosphate nanoparticle were firstly characterized by powder X-ray diffraction as shown in Figure 2. The graph shows that the pattern consists of peak at specific Bragg's angle depicting the crystalline nature of the material. The X-ray data was compared with JCPDS card number 32-0199 which suggests that material belongs to monoclinic phase of the monazite structure with lattice parameters $a=6.79(6) \AA, b=7.03(8) \AA, c=6.43(6) \AA$, and $\beta=103^{\circ} 28^{\prime}$ and space group $\mathrm{P} 2_{1 / n}$. In the XRD pattern, no additional peak of other phases was observed, thereby indicating the confirmation of the composition. Fang et al. [17] demonstrated that the rare earth orthophosphates $\left(\mathrm{RPO}_{4}\right)$ have structural transition from the hexagonal to the monoclinic by calcinations at high temperature. Obviously, monoclinic is a high temperature phase and the hexagonal

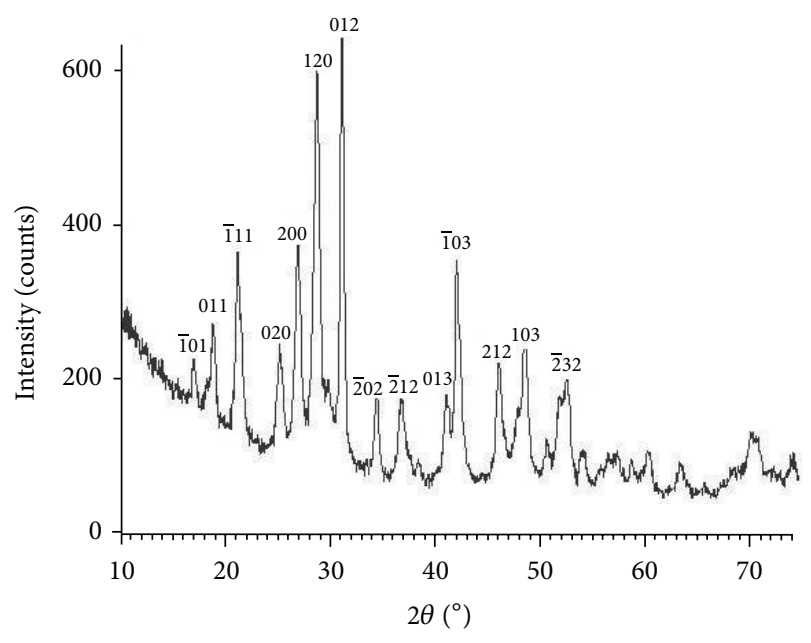

FIgURE 2: Powder X-ray diffraction pattern of cerium orthophosphate $\left(\mathrm{CePO}_{4}\right)$ nanoparticles showing well-defined peaks at specific Bragg's angle.

TABLE 1: Data regarding interatomic $(d)$ spacing, the $\{h k l\}$ planes corresponding to specific $2 \theta$ angles.

\begin{tabular}{lcc}
\hline$d$-Spacing & 2 theta $(\theta)$ & $\{h k l\}$ planes \\
\hline 4.56 & 18.93 & 011 \\
4.82 & 21.23 & -111 \\
3.62 & 25.38 & 020 \\
3.32 & 26.85 & 200 \\
3.10 & 28.77 & 120 \\
2.87 & 31.12 & 012 \\
2.14 & 42.03 & -103 \\
1.97 & 46.07 & 212 \\
1.88 & 48.47 & 103 \\
1.74 & 52.55 & -232 \\
\hline
\end{tabular}

is a low temperature phase. The details of the XRD pattern depicting interatomic $(d)$ spacing and corresponding $(h k l)$ planes are given in Table 1. The line broadenings of diffraction peaks can be used to calculate the crystallite size by Scherer's formula:

$$
D=\frac{k \lambda}{\beta \operatorname{Cos} \theta},
$$

where " $D$ " is the crystallite size (nm), " $\lambda$ " is the wavelength of monochromatic X-ray beam $(\AA)(\lambda=1.54184 \AA$ for CuK $\alpha$ radiation), " $\beta$ " is the full width at half maximum for the diffraction peak under consideration (rad.), " $\theta$ " is the diffraction angle $\left({ }^{\circ}\right)$, and " $k$ " is a constant varying with crystal habit and chosen to be 0.9 . The crystallite size comes out to be $49.3 \mathrm{~nm}$. Figure 3 is the graph showing the particle size $(\mathrm{nm})$ by Zeta particle size analyzer. From the particle size analyzer graph and XRD results, it may be concluded that the synthesized cerium orthophosphate is in the nanoscale range.

Figures 4(a) and 4(b) show scanning electron micrograph which reveals the surface morphology. These nanoparticles 


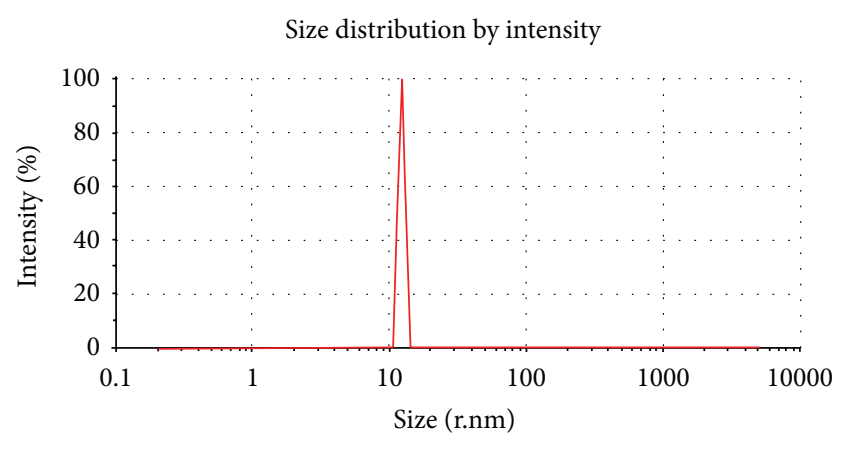

FIGURE 3: Graph obtained from the zetasizer Nano ZS analyzer which shows the particle size of cerium orthophosphate $\left(\mathrm{CePO}_{4}\right)$ in nanometer range.

are composed of agglomerated spherical particles. The possible growth mechanism for the formation of agglomerated spherical particles requires the surface potential to be low so that the attractive interaction between the grain boundaries dominates over the repulsive interaction forces. So the magnitude of the attractive interaction depends on the various factors like ionic strength, the dielectric constant of the solvent, and its viscosity which affects the kinetic agglomeration [18-20]. Further insight into the morphology and the microstructure of the prepared material was investigated under transmission electron microscope (TEM) and selected area electron diffraction pattern (SAED). Figure 5(a) clearly depicts the nanosphere with partial agglomeration having grain size in the range of $30-50 \mathrm{~nm}$ which is comparable to the crystallite size calculated by Scherer formula and from zeta particle size analyzer. The three-dimensional porous network structure of dried powder results in the formation of interspace between the particles, which inhibits the growth of particles at all directions and hence the particle shape is spherical instead of any other shape. Therefore, the coprecipitation process in the present investigation leads to homogenous powder with small spherical particles with a narrow size distribution. The corresponding selected area electron diffraction (SAED) pattern in the inset of Figure 5(b) reveals that the samples are consistent with the high crystallinity, and diffraction spots can be indexed as the phase formed is purely monoclinic in monazite structure which has also been confirmed from the powder XRD results.

The spectrum obtained from energy dispersive X-ray analysis (EDAX) is shown in Figure 6. The EDAX spectrum shows peaks corresponding to all the major elements present in the grown composition as should be expected in case of cerium orthophosphates. The spectra show peaks corresponding to all major elements like cerium, oxygen, and phosphorous. No such impurity was found in the grown material. The weight $\%$ and atomic $\%$ as observed in the experiment are given in Table 2.

3.2. Thermal Analysis. Thermogravimetric and differential thermal analyses (TGA/DTA) were used to identify different phase transition and to assess the stability of a prepared material. Figure 7 shows the recorded thermograph for cerium orthophosphate dried at $100^{\circ} \mathrm{C}$. TGA/DTA was carried out between $14^{\circ} \mathrm{C}$ and $1000^{\circ} \mathrm{C}$ at uniform heating rate of $10^{\circ} \mathrm{C} / \mathrm{min}$ and the mass was found to lose continuously as a function of temperature. The material starts to decompose at $21^{\circ} \mathrm{C}$ and decomposition went up to $335^{\circ} \mathrm{C}$; thereafter the material is thermally stable up to $1000^{\circ} \mathrm{C}$. The total weight loss observed is $15.81 \%$. From the graph, it is clear that the thermal decomposition can be divided into three stages. The first stage of decomposition begins at $21^{\circ} \mathrm{C}$ and terminates at $127^{\circ} \mathrm{C}$. During this temperature range, the mass loss observed is 9.31\%. In this first stage of decomposition, the endothermic peak is observed at $54^{\circ} \mathrm{C}$ which is attributed to the loss of physisorbed water. The second stage of decomposition starts at around $127^{\circ} \mathrm{C}$ and is completed at around $255^{\circ} \mathrm{C}$ and net weight loss observed is $3.92 \%$. Second stage of decomposition involves conversion of hydrated hexagonal cerium orthophosphate into anhydrous in nature as indicated in the following equation [21]:

$$
\left(\mathrm{CePO}_{4} \cdot n \mathrm{H}_{2} \mathrm{O}\right)_{\text {Hexagonal }} \Longleftrightarrow\left(\mathrm{CePO}_{4}\right)_{\text {Hexagonal }}+n \mathrm{H}_{2} \mathrm{O}
$$

The third stage of decomposition occurs in the temperature range from 255 to $335^{\circ} \mathrm{C}$. The weight loss in this stage is $2.58 \%$. During this decomposition stage, this weight loss is accompanied by an exothermic peak at $285^{\circ} \mathrm{C}$ which is attributed to the transformation of cerium orthophosphate from the amorphous state to the crystalline phase. After the third decomposition stage $\left(255-335^{\circ} \mathrm{C}\right)$, the material is thermally stable up to $1000^{\circ} \mathrm{C}$. A weak exothermic peak at $817^{\circ} \mathrm{C}$ may be due to the crystallization of monoclinic monazite, cerium orthophosphate from hexagonal form $\left(\left(\mathrm{CePO}_{4}\right)_{\text {Hexagonal }} \rightarrow\left(\mathrm{CePO}_{4}\right)_{\text {Monoclinic }}\right)$. From the thermal analysis of the system, we can therefore confirm that the product formed is in the monoclinic phase above $800^{\circ} \mathrm{C}$ which support the results obtained by powder XRD.

3.3. Fourier Transform Infrared Spectroscopy (FTIR). In order to identify and characterize the inorganic species and analyse the chemical bonds, functional groups, and internal structure of molecules present in the grown nanomaterial, Fourier transform infrared spectroscopy (FTIR) was used. Figure 8 shows the FTIR spectra of cerium orthophosphate $\left(\mathrm{CePO}_{4}\right)$. Fundamentals IR frequencies observed in other phosphate compounds were also found in the present case, which confirms the presence of orthophosphate group in the grown material. The band observed in the range 2885.51$2341.58 \mathrm{~cm}^{-1}$ shows the presence of absorption of water vibration in addition to the wide bands associated with the $\mathrm{OH}$ group and another peak at 1635.64 is due to the scissor bending mode of associated water molecule [21]. The bands around wave numbers $1043.49,623.01$, and $543.93 \mathrm{~cm}^{-1}$ correspond to $\mathrm{P}-\mathrm{O}$ stretching, $\mathrm{O}=\mathrm{P}-\mathrm{O}$ bending, and $\mathrm{O}-\mathrm{P}-$ $\mathrm{O}$ bending mode of vibration, respectively. The bands from orthophosphate $\left(\mathrm{PO}_{4}{ }^{3-}\right)$ functional group appeared at 493.78 to $395.41 \mathrm{~cm}^{-1}$ in the lanthanide phosphates of monoclinic (monazite structure) and agree well with the literature data [22]. Table 3 gives complete information about the type of 


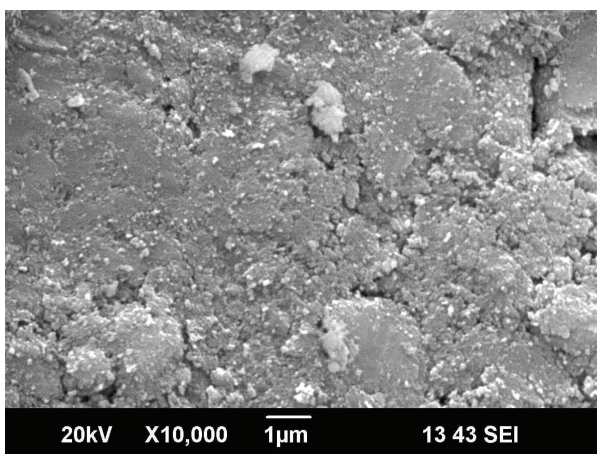

(a)

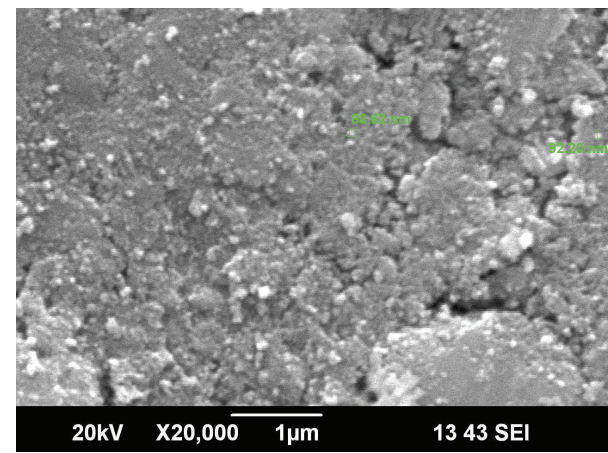

(b)

Figure 4: (a) Scanning electron micrograh of $\mathrm{CePO}_{4}$ at lower magnification. (b) Scanning electron micrograph reveals the nanoparticles are composed of agglomerated spherical particles.

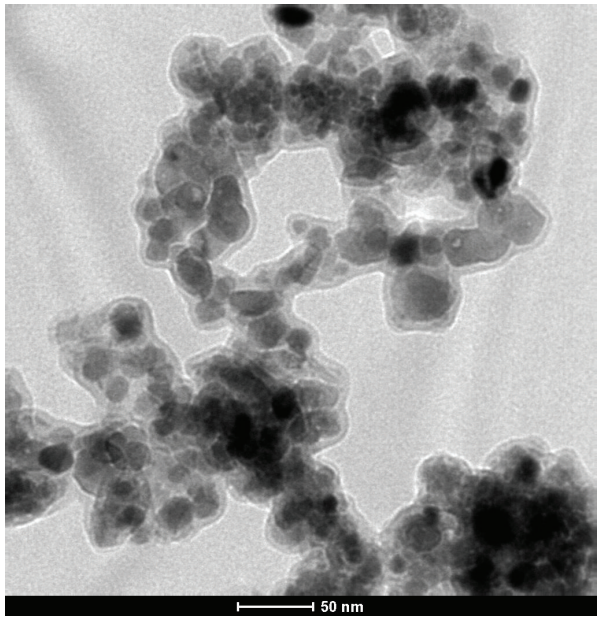

(a)

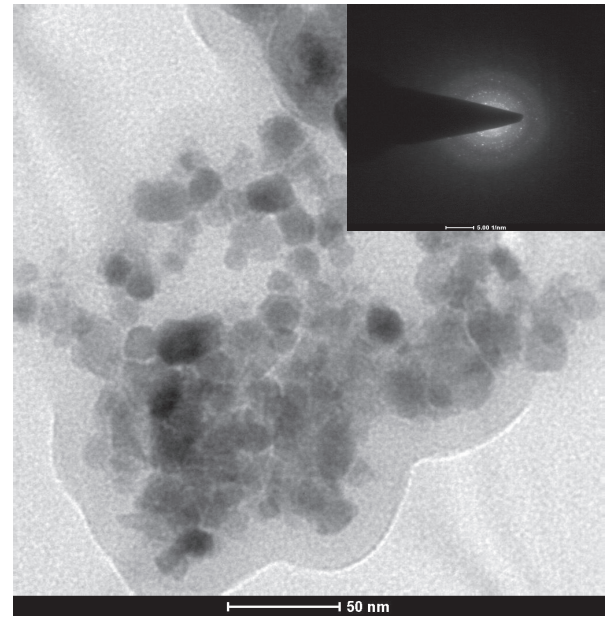

(b)

FIGURE 5: (a) TEM micrograph clearly depicting nanosphere morphology having grain size in the range of 30-50 nm. (b) TEM micrograph and corresponding SAED patterns of cerium orthophosphate nanoparticles.

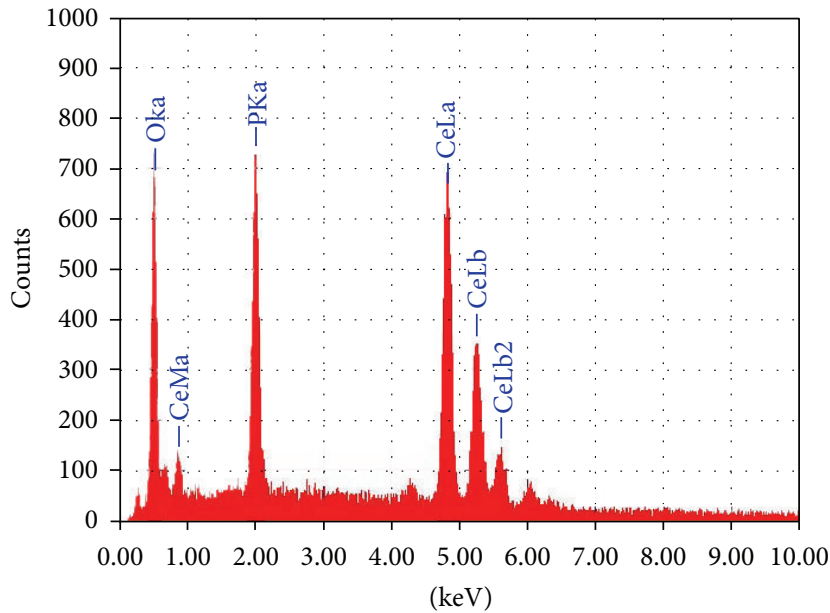

FIGURE 6: Energy dispersive X-ray analysis (EDAX) spectrum revealing the presence of all the major elements present in cerium orthophosphate $\left(\mathrm{CePO}_{4}\right)$.
TABLE 2: Data regarding weight\% and atomic\% present in the cerium orthophosphate $\left(\mathrm{CePO}_{4}\right)$ composition as observed in the experiment.

\begin{tabular}{lccc}
\hline Elements & Weight\% & Atomic\% & $\mathrm{KeV}$ \\
\hline Oxygen $(\mathrm{O})$ & 11.95 & 43.53 & 0.525 \\
Phosphorous $(\mathrm{P})$ & 13.53 & 25.47 & 2.013 \\
Cerium $(\mathrm{Ce})$ & 74.52 & 31 & 4.839 \\
\hline
\end{tabular}

functional groups present in the grown material along with their frequency bands.

\subsection{Optical Characterization}

3.4.1. UV-VIS-NIR Absorption Spectrophotometer. Rare earth compounds are one of the most important types of phosphors so it is essential to understand their optical properties, namely, electronic transitions and optical band gap energy. The UV-VIS-NIR absorption spectrophotometer for cerium 


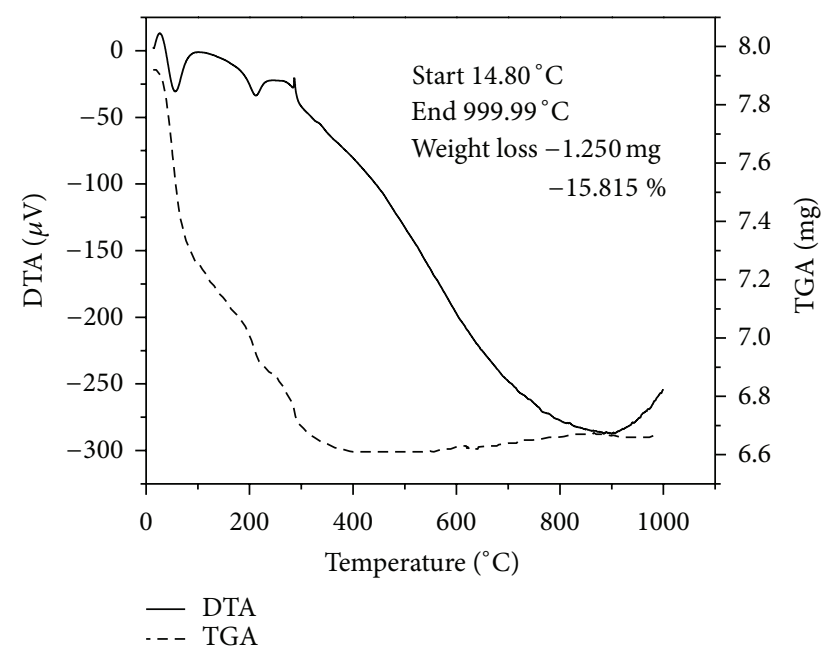

FIGURE 7: Thermograph showing simultaneous recording of TGA and DTA curves for cerium orthophosphate $\left(\mathrm{CePO}_{4}\right)$.

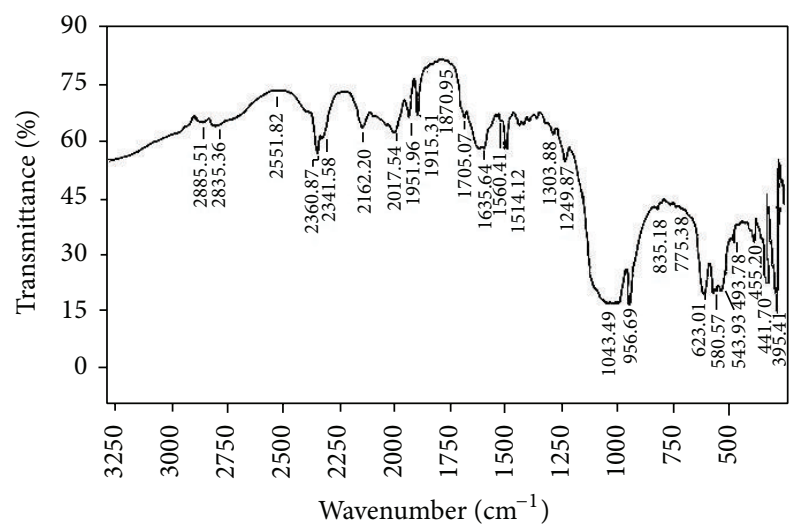

FIGURE 8: FTIR spectrum depicting the various functional groups present in the grown composition.

TABLE 3: Presence of various functional groups along with their frequency bands.

\begin{tabular}{lcc}
\hline Serial number & Assignments of bands/peak & IR bands $\left(\mathrm{cm}^{-1}\right)$ \\
\hline 1 & OH stretching & $2885.51-2341.58$ \\
2 & H-O-H bending & $1635.64-1514.12$ \\
3 & P-O stretching & 1043.49 \\
4 & O=P-O bending & 623.01 \\
5 & O-P-O bending mode of vibration & 543.93 \\
6 & $\mathrm{PO}_{4}{ }^{3-}$ vibration & $493.78-395.41$ \\
\hline
\end{tabular}

orthophosphate is shown in Figure 9. It can be seen that there are two absorption bands at 208 and $274 \mathrm{~nm}$ in the ultraviolet range which is assigned to transitions from ground state ${ }^{2} \mathrm{~F}_{5 / 2}$ to the excited state, namely, ${ }^{2} \mathrm{D}_{5 / 2}$ and ${ }^{2} \mathrm{D}_{3 / 2}$ energy level. The cerium absorption band shows a weak extension from 300 to $450 \mathrm{~nm}$, which is caused by the presence of a small amount of $\mathrm{Ce}^{4+}$ and a small peak is observed at 1452 and $1939 \mathrm{~nm}$ due to the presence of phosphate in the NIR region.

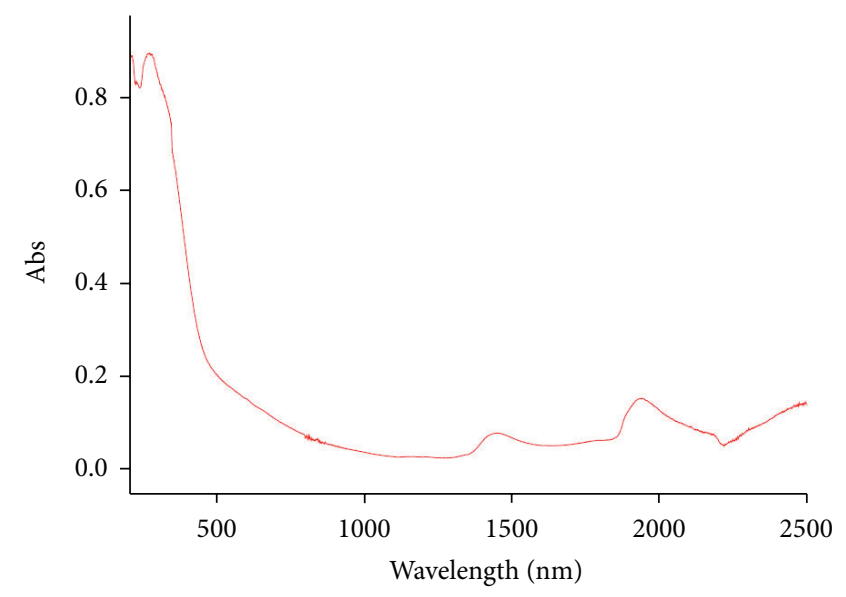

FIGURE 9: UV-VIS-NIR absorption spectrum for cerium orthophosphate $\left(\mathrm{CePO}_{4}\right)$.

The obtained results are consistent with the data for transition of $\mathrm{Ce}^{3+}$ where the transition in case of $\mathrm{Ce}^{3+}$ is assigned from $4 \mathrm{f}$ ground state $\left({ }^{2} \mathrm{~F}_{5 / 2}\right)$ to the $5 \mathrm{~d}$ energy level split $\left({ }^{2} \mathrm{D}_{5 / 2},{ }^{2} \mathrm{D}_{3 / 2}\right)$ within monoclinic crystal field [17, 23]. UVVisible absorption spectra also give the optical band gap of the material. The energy band gap is related to the absorption coefficient " $\alpha$ " by the Tauc relation, $\alpha h v=A\left(h v-E_{g}\right)^{n}[24]$, where " $A$ " is constant, " $h \nu$ " is the photon energy $(\nu=c / \lambda)$, " $E_{g}$ " is the band gap energy of the material, and $n=1 / 2$ for an allowed direct transition. For allowed direct transition, the band gap energy can be obtained from extrapolation of the straight line $(\alpha h \nu)^{2}$ versus $h v$ as shown in Figure 10. From the intersection of the extrapolated linear portion, the optical band gap energy $\left(E_{g}\right)$ of the material was found to be $1.07 \mathrm{eV}$; it means the absorption of photon with energy is greater than the optical band gap energy for direct transition from the occupied state in the valence band to unoccupied states in the conduction band. From the optical results, one can conclude that the cerium orthophosphate shows the properties of direct band gap material. In direct band gap material the electron wave vector remains the same (there is no phonon interaction); that is, if the momentum of electrons and holes is the same in both the conduction band and valence band, an electron can directly emit a photon.

3.4.2. Photoluminescence. In addition, optical property of the material was also analyzed by photoluminescence (PL) emission spectrum using the excitation wavelength of $330 \mathrm{~nm}$ as shown in Figure 11. The emission spectra of $\mathrm{Ce}^{3+}$ show a strong ultraviolet broad band at $400 \mathrm{~nm}$ which is caused by the $5 \mathrm{~d}-4 \mathrm{f}$ emission. The inset spectra (Figure 11) show $\mathrm{Ce}^{3+}$ emission band ranging from 388 to $418 \mathrm{~nm}$ which consists of the expected doublet peak arising from the ${ }^{2} \mathrm{D}_{3 / 2}$ excited state to the ground state ${ }^{2} \mathrm{~F}_{7 / 2}$ and ${ }^{2} \mathrm{~F}_{5 / 2}$. The shape of emission band at shorter wavelength ${ }^{2} \mathrm{D}_{3 / 2}-{ }^{2} \mathrm{~F}_{5 / 2}$ overlapped with ${ }^{2} \mathrm{D}_{3 / 2}-{ }^{2} \mathrm{~F}_{7 / 2}$ emission bands depends on the Ce/P ratio [25]. From the emission spectra, it can be found that the value 


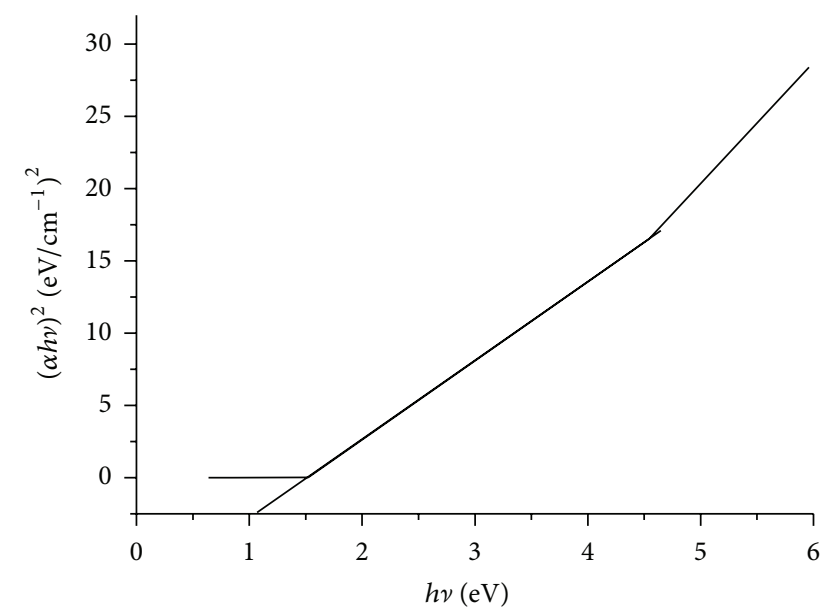

FIGURE 10: Tauc plot of $(\alpha h \nu)^{2}$ versus $h v$ for cerium orthophosphate $\left(\mathrm{CePO}_{4}\right)$.

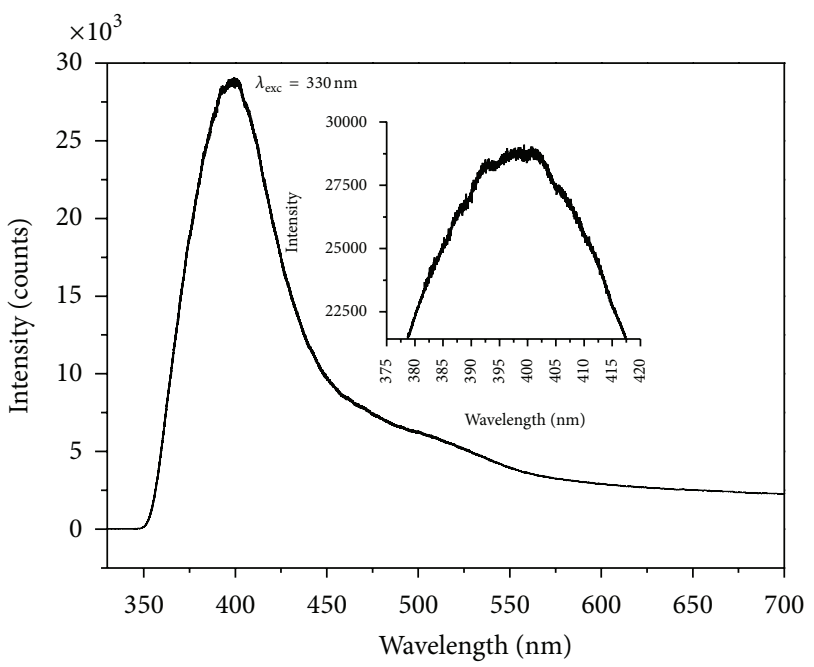

Figure 11: Photoluminescence (PL) emission spectrum using excitation wavelength $330 \mathrm{~nm}$.

of the luminescence intensity is very high approximately 30,000 . This high value of emission intensity shows less impurity and defects present on the surface of the grown material which is important pathway for nonradiative relaxation in nanomaterials. The defects in materials can form the quenching centres which lead to nonradiative recombination and luminescence quenching [8].

3.5. Electrical Properties. The investigation of electrical property is an elegant tool for understanding the dielectric behaviour of the material in response to an applied electric field. The study includes finding dependence of dielectric constant $\left(\varepsilon^{\prime}\right)$ and dielectric loss $(\tan \delta)$ on temperature and frequency. In order to carry out these investigations, the agglomerated nanoparticle was mixed with 1-2\% PVA (polyvinyl alcohol) which acts as a binder and then pressed into a shape of circular pellet of the size $13.11 \mathrm{~mm}$ in diameter

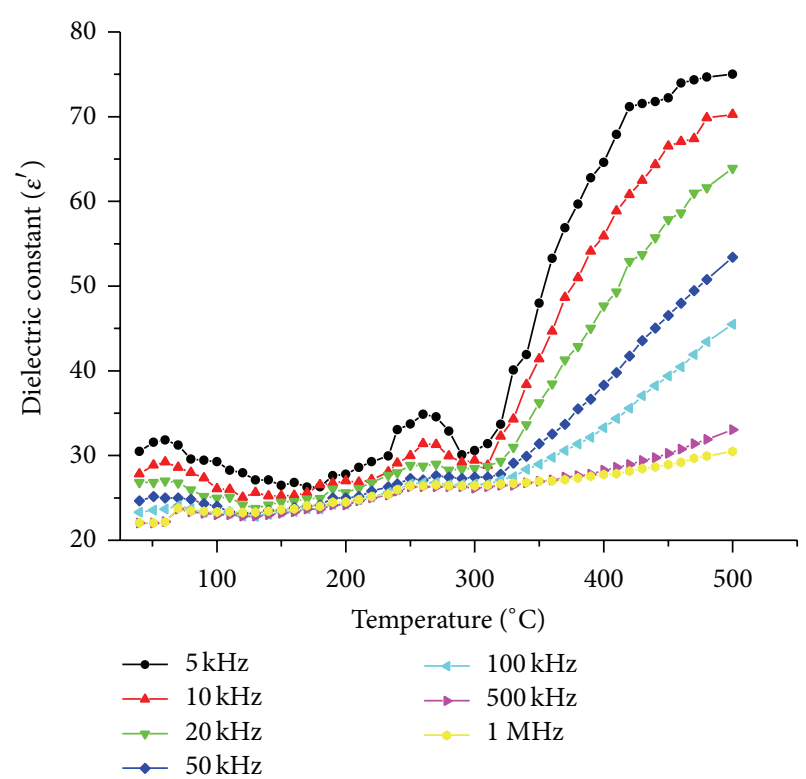

FIGURE 12: Plot showing variation of dielectric constant with temperature for different frequencies.

and $1.43 \mathrm{~mm}$ in thickness with the help of hydraulic press. The pellet was heated up to a temperature of $250^{\circ} \mathrm{C}$ at a heating rate of $2^{\circ} \mathrm{C} / \mathrm{min}$. before performing any measurement in order to overcome the effect of binder. The conducting silver paste was applied on both sides of the circular pallet which acted as capacitor with the material as dielectric. The material was then mounted on specially designed two terminal sample holders. The instrument directly provides the value of capacitance $(C)$ and dielectric loss $(\tan \delta)$. The dielectric constant was calculated using the relation:

$$
\varepsilon^{\prime}=\frac{C t}{\varepsilon_{0} A},
$$

where " $C$ " is the capacitance (F), " $t$ " is the thickness (m), " $A$ " is the area $\left(\mathrm{m}^{2}\right)$, and " $\varepsilon_{0}$ " is the absolute permittivity in the free space having a value of $8.854 \times 10^{-12} \mathrm{Fm}^{-1}$.

\subsubsection{Dependence of the Dielectric Constant and Loss Tangent} on Temperature. Figure 12 shows the variation of dielectric constant $\left(\varepsilon^{\prime}\right)$ with temperature $\left(40-500^{\circ} \mathrm{C}\right)$ as a function of frequencies $(5 \mathrm{kHz}-1 \mathrm{MHz})$. The dielectric curve shows two anomalies, one at $60^{\circ} \mathrm{C}$ and another at $260^{\circ} \mathrm{C}$. This behaviour was observed for other materials which exhibit two-phase transition [26]. In first phase of transition, the value of $\varepsilon^{\prime}$ increases with increase in temperature attaining a maximum value of 31 followed by a decreasing pattern. The second phase transition occurs at $260^{\circ} \mathrm{C}$ and the maximum value of $\varepsilon^{\prime}$ is 34 . The first transition is attributed to the space charge polarization effect and the second phase transition may be due to ferroelectric to paraelectric transition. Similar behaviour was also observed in the thermal analysis results. From the thermal analysis graph, the peak observed at $285^{\circ} \mathrm{C}$ is nearly equal to the peak observed at $260^{\circ} \mathrm{C}$ in 


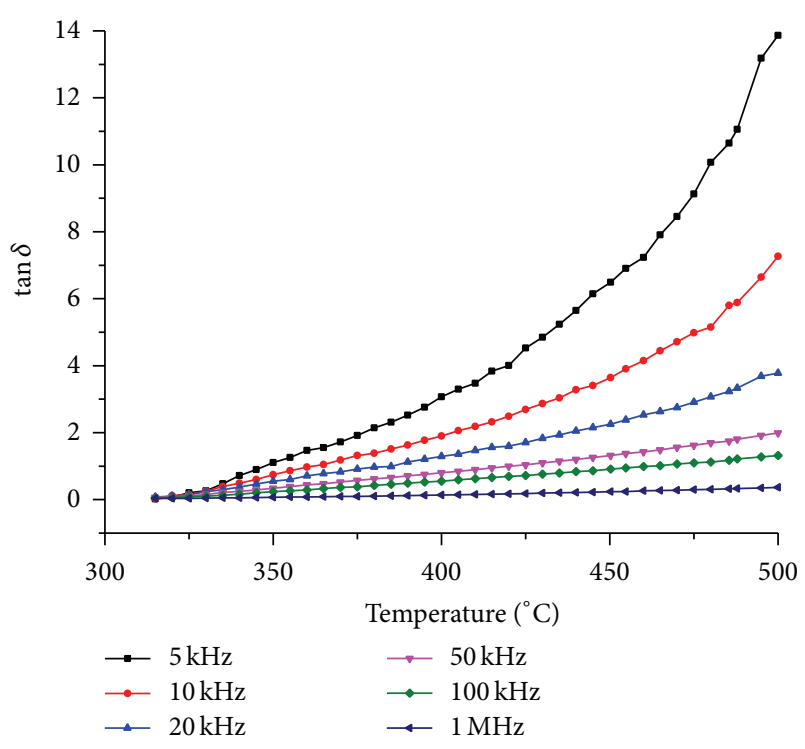

FIgURE 13: Plot showing variation of dielectric loss $(\tan \delta)$ with temperature for different frequencies.

the dielectric results suggesting that the transition takes place in the material. During this phase transition, the peak observed is broadened and as frequency increases from $5 \mathrm{kHz}$ to $50 \mathrm{kHz}$ the peak around the dielectric constant becomes more broadened and the dielectric shifts towards the higher temperature. At higher frequencies $(1 \mathrm{MHz})$, the value of dielectric constant shows less variation with temperature because space charge polarization decreases as the frequency increases. So, one can observe that the value of transition temperature shifts towards higher temperature with increase in frequency thereby showing the relaxational behaviour of the material. For most of the relaxor ferroelectrics, the peak of the dielectric constant $\left(\varepsilon^{\prime}\right)$ shifts to higher temperature with increasing frequency, which has been attributed to decreasing relaxation time with increasing temperature [27]. However, after the second phase transition and above $300^{\circ} \mathrm{C}$ the value of dielectric constant $\left(\varepsilon^{\prime}\right)$ shows further increase with increase in temperature. The maximum value of dielectric constant $\left(\varepsilon^{\prime}\right)$ obtained for $5 \mathrm{kHz}$ at $500^{\circ} \mathrm{C}$ is 77 , but due to instrument constraint we cannot perform our experiment beyond $500^{\circ} \mathrm{C}$. The dielectric loss $(\tan \delta)$ was observed in the temperature range of $315-500^{\circ} \mathrm{C}$ (Figure 13) and behaviour is almost similar to that of variation of dielectric constant $\left(\varepsilon^{\prime}\right)$ within this temperature range.

3.5.2. Diffusivity Study. The region around the dielectric peak is broadened, which is a diffuse phase transition. The diffuse phase transition (DPT) takes place in materials where the composition fluctuations lead to large fluctuations in the Curie temperature. The structural disorder arises due to the presence of a number of voids and impurities of different size. The degree of diffusivity $(\gamma)$ is calculated using the expression:

$$
\frac{1}{\varepsilon^{\prime}}-\frac{1}{\varepsilon_{\max }^{\prime}}=A\left(T-T_{c}\right)^{\gamma}
$$

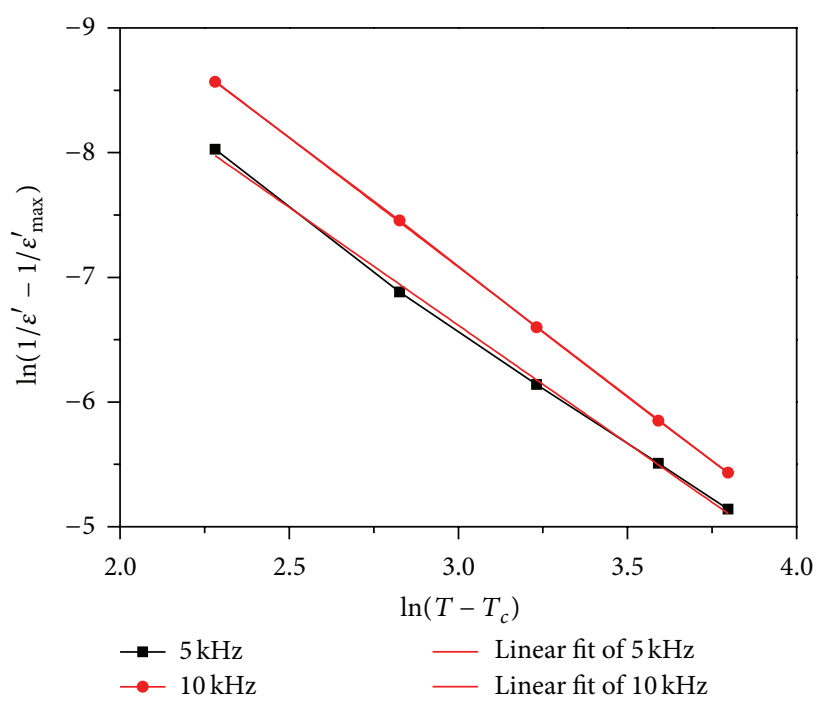

FIGURE 14: $\ln \left(1 / \varepsilon^{\prime}-1 / \varepsilon_{\max }^{\prime}\right)$ versus $\ln \left(T-T_{c}\right)$ curves at 5 and $10 \mathrm{kHz}$ for diffuse phase transition.

Here $\varepsilon_{\max }^{\prime}$ is the peak value of the dielectric constant and $\gamma$ is the critical exponent which lies in the range $1<\gamma \leq 2 . \gamma$ $=1$ represents the ideal Curie-Weiss behaviour while being between 1 and 2 indicates diffuse behaviour [28]. The diffuse phase transition in ferroelectric is characterized by extending the phase transition in a wide temperature interval around the transition temperature where the dielectric constant assumes its maximum value. Figure 14 shows the variation of $\ln$ $\left(1 / \varepsilon^{\prime}-1 / \varepsilon_{\max }^{\prime}\right)$ with $\ln \left(T-T_{c}\right)$ at 5 and $10 \mathrm{kHz}$. The value of $\gamma$ calculated from the slope of the curves comes out to be 1.8 at $5 \mathrm{kHz}$ and 2.0 at $10 \mathrm{kHz}$. Thus, the value of " $\gamma$ " suggests the diffuse phase transition, which may be due to the compositional fluctuations and structural disordering in the arrangement of cations in one or more crystallographic sites in the structure that finally results in a microscopic heterogeneity in the grown materials with local Curie points [29].

\subsubsection{Dependence of Dielectric Constant and Loss Tangent on} Frequency. The dependence of dielectric constant $\left(\varepsilon^{\prime}\right)$ and loss tangent $(\tan \delta)$ on frequency of the applied ac field was studied in the temperature range of $40-500^{\circ} \mathrm{C}$ and a frequency range of $5 \mathrm{kHz}$ to $1 \mathrm{MHz}$. Figures 15 and 16 show that the dielectric constant $\left(\varepsilon^{\prime}\right)$ and dielectric loss go on decreasing continuously with frequency in the lower frequency range and to attain saturation at $1 \mathrm{MHz}$. The continuous decrease in the value of the dielectric constant $\left(\varepsilon^{\prime}\right)$ and loss tangent with increasing frequency may be attributed to different types of polarisation, namely, ionic, electronic, dipolar, and interfacial or space charge polarisation at low frequencies [30]. This continuous fall occurs because dipoles are not able to follow faithfully the impressed oscillating field and the low value of dielectric constant $\left(\varepsilon^{\prime}\right)$ was observed at high frequencies. Similarly, the loss tangent also decreases in the same manner like dielectric constant. The observed dielectric constant at 


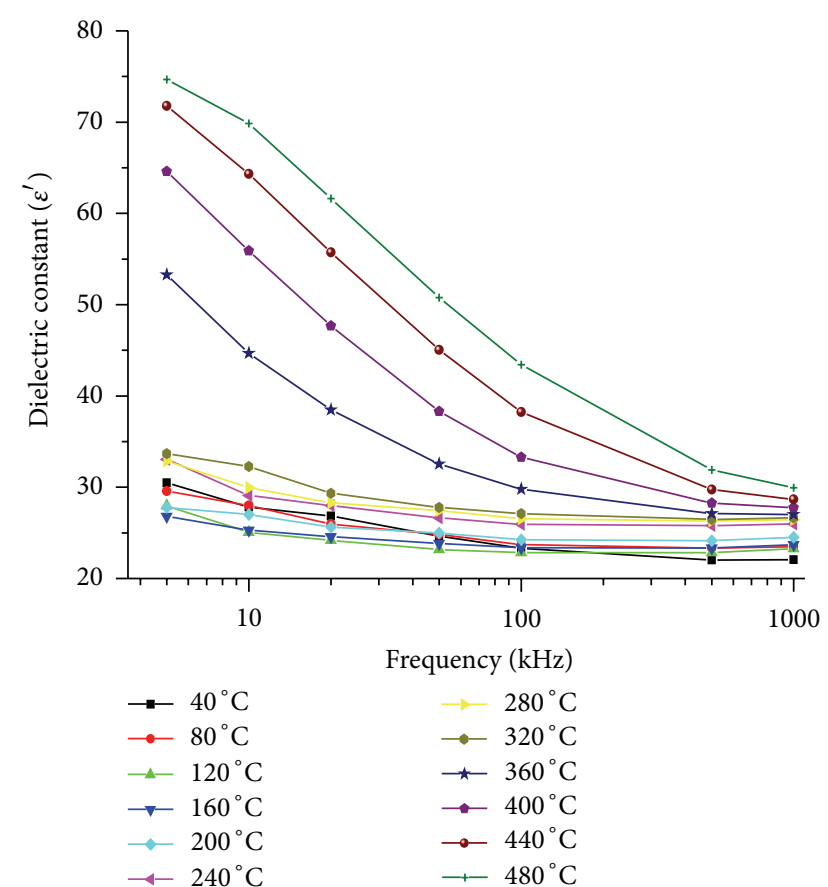

FIGURE 15: Graph showing the variation of dielectric constant with frequency at different temperatures.

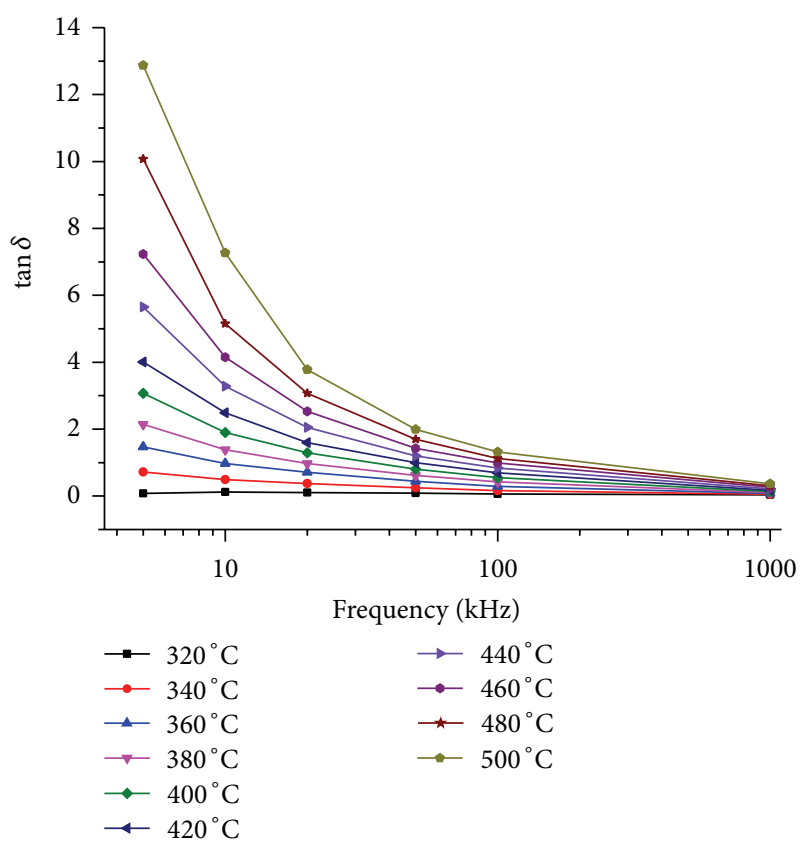

FIGURE 16: Graph showing the variation of dielectric loss with frequency at different temperature.

low frequencies can be explained on the basis of the MaxwellWagner model. In this model, the dielectric structure consists of two layers: the first layer shows a large number of grains that act as a conducting medium at higher frequencies and the second layer consists of grain boundaries that act as a highly resistive medium at low frequencies [31]. In cerium

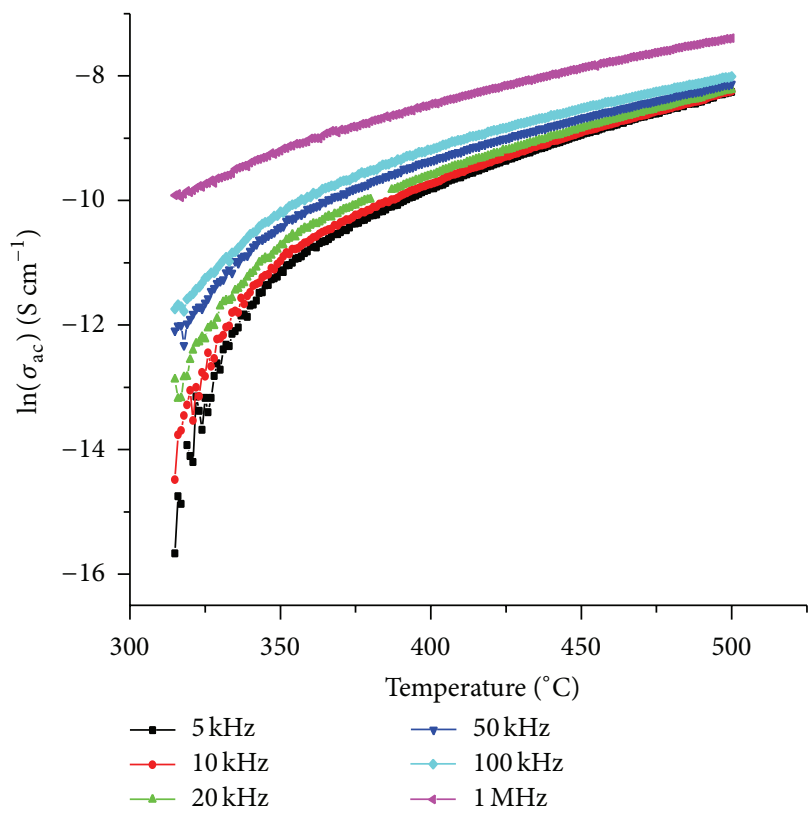

FIGURE 17: Graph showing the variation of $\ln \left(\sigma_{\mathrm{ac}}\right)$ with temperatures at various frequencies.

orthophosphate nanoparticles, the polarisation mechanism at low frequency is explained as a local displacement of electrons by the hopping mechanism between $\mathrm{Ce}^{3+} / \mathrm{Ce}^{4+}$ and an orientation of dipoles in the direction of the applied ac field. At low frequencies, the dielectric constant value is very high because the charge carriers are collected at the boundaries between the conductive grain region and the highly resistive grain boundary region. When the frequency increases, the electric dipoles and the $\mathrm{Ce}^{3+} / \mathrm{Ce}^{4+}$ electrons transfer decreases the net displacement of charge in one direction thereby decreasing the dielectric constant value

3.5.4. AC Conductivity and Activation Energy. In order to understand and authenticate the conduction mechanism, the alternating current conductivity $\sigma_{\mathrm{ac}}\left(\Omega^{-1} \mathrm{~m}^{-1}\right)$ was calculated in the high temperature region using the relation:

$$
\sigma_{\mathrm{ac}}=2 \Pi f_{\mathrm{ac}} \varepsilon_{\mathrm{o}} \varepsilon^{\prime} \tan \delta,
$$

where " $f_{\mathrm{ac}}$ " is the frequency of the applied field $(\mathrm{kHz})$ " $\varepsilon_{\mathrm{o}}$ " is the absolute permittivity of free sample having a value of $8.854 \times 10^{-12} \mathrm{Fm}^{-1}$, " $\varepsilon^{/}$" is the dielectric constant and " $\tan \delta^{\prime}$ is the dielectric loss.

The variation of ac conductivity was measured at different frequencies from $5 \mathrm{kHz}$ to $1 \mathrm{MHz}$ in the temperature range of $315-500^{\circ} \mathrm{C}$. Figure 17 shows the variation of ac conductivity " $\ln \left(\sigma_{\mathrm{ac}}\right)$ " with temperature. It was observed from the graph that the ac conductivity goes on increasing with increasing temperature. The influence of conductivity has been explained by considering the mobility of charge carrier responsible for hopping. As temperature increases, the mobility of hopping ions also increases thereby increasing conductivity. The variation of ac conductivity " $\ln \left(\sigma_{\mathrm{ac}}\right)$ " with frequency at different temperatures ranging from 340 to 


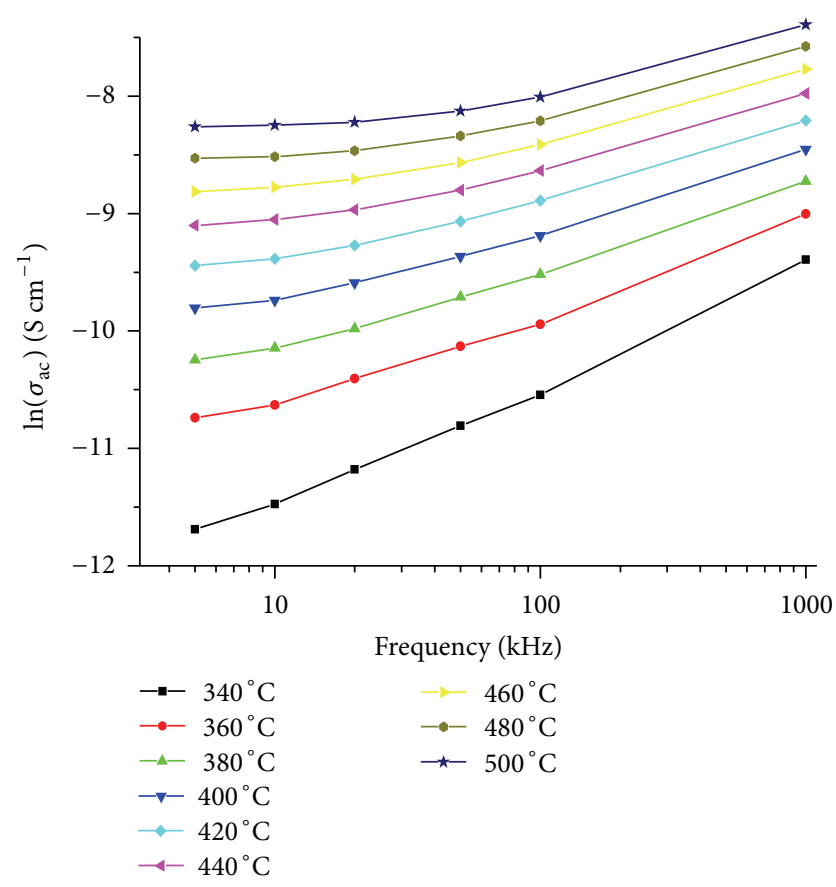

Figure 18: Variation of $\ln \left(\sigma_{\mathrm{ac}}\right)$ with frequency at different temperatures.

$500^{\circ} \mathrm{C}$ is shown in Figure 18. From the graph, it can be observed that the dependence of ac conductivity increases with increasing frequency at all temperature which is characteristics feature of material where hopping mechanism dominates. In the low frequency region, the conductivity was identical to the dc conductivity and was independent of frequency [32]. In the low frequency range, the applied field is not enough to initiate the hopping conduction. Therefore, the range of the low frequency conductivity plateau $\left(\sigma_{\mathrm{ac}}\right)$ was found to increase with temperature. As frequency increases, ac conductivity increases due to the strong mobility of charge carriers. One can conclude that the conductivity is a function of both temperature and frequency of the applied field as has been reported for other materials [33-35]. At high frequency, ac conductivity $\left(\sigma_{\mathrm{ac}}\right)$ increases linearly with frequency obeying the power law: $\sigma_{\mathrm{ac}}=A \omega^{n}$, where " $A$ " is the temperature dependent constant and " $n$ " is the frequency exponent [33]. The variation of frequency exponent parameter " $n$ " with temperature gives information about the specific mechanism. Figure 19 shows the variation of the exponent " $n$ " with temperature and it is clear that with the increase of temperature, the value of " $n$ " goes on decreasing. The decrease of $(n)$ suggests that the correlated barrier hopping (CBH) [36] model is the predominant ac conduction mechanism, which considers the hopping of charge carriers between two sites over a barrier separating them.

The variation of ac conductivity $\left(\sigma_{\mathrm{ac}}\right)$ with temperature favours the thermally activated transport properties obeying Arrhenius formula. The activation energy for cerium

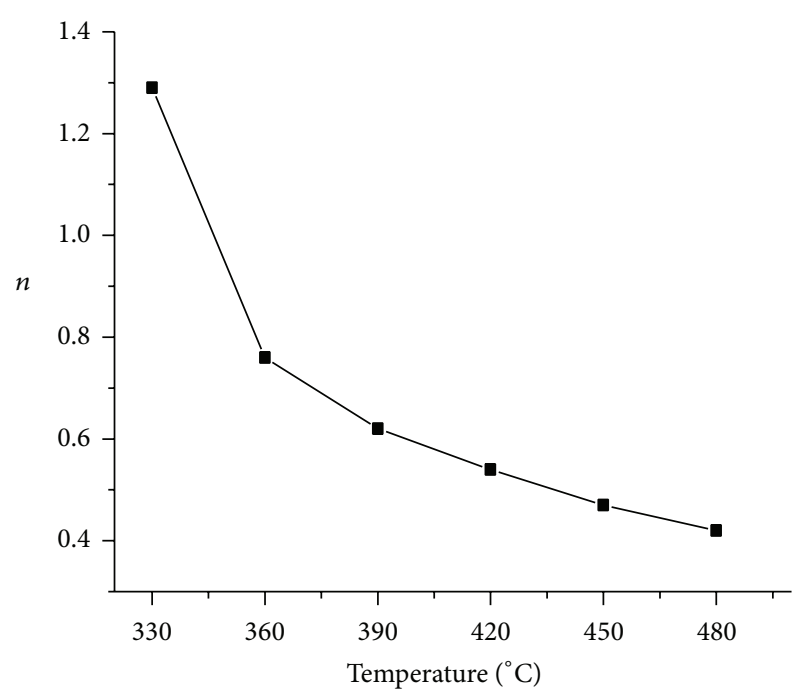

FIGURE 19: The variation of frequency exponent parameter $(n)$ with temperature for $\mathrm{CePO}_{4}$ nanoparticles.

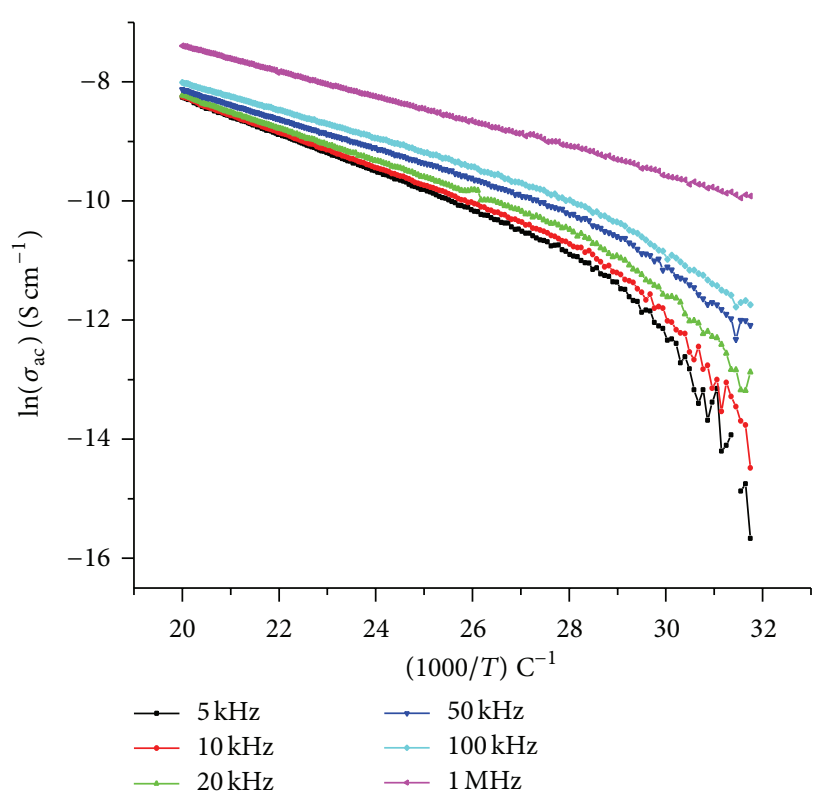

FIGURE 20: Graph showing the variation of $\ln \left(\sigma_{\mathrm{ac}}\right)$ with $1000 T^{-1}$ at different frequency.

orthophosphate nanoparticles was calculated from Arrhenius plot of $\ln \sigma_{\mathrm{ac}}$ using the relation:

$$
\sigma_{\mathrm{ac}}=\sigma_{0} \exp \cdot\left(-\frac{E_{a}}{K_{B} T}\right)
$$

where " $\sigma_{\mathrm{ac}}$ " is the conductivity at temperature " $T$," " $E_{a}$ " is the activation energy for the electrical process, and " $K_{B}$ " is the Boltzmann constant. Activation energy was calculated from the slope of the graph (Figure 20) showing the variation of $\ln \left(\sigma_{\mathrm{ac}}\right)$ with $1000 T^{-1}$ at different frequencies. The activation energy at frequencies $5,10,20,50,100$, and $1000 \mathrm{kHz}$ was calculated and is given in Table 4 . The values of activation 
TABLE 4: Activation energy calculated on the basis of Arrhenius formula for cerium orthophosphate $\left(\mathrm{CePO}_{4}\right)$ at different frequencies.

\begin{tabular}{lcc}
\hline Serial number & Frequency $(\mathrm{kHz})$ & Activation energy $(\mathrm{eV})$ \\
\hline 1 & 5 & 0.037 \\
2 & 10 & 0.033 \\
3 & 20 & 0.029 \\
4 & 50 & 0.026 \\
5 & 100 & 0.025 \\
6 & 1000 & 0.018 \\
\hline
\end{tabular}

energy comes out to be $0.037,0.033,0.029,0.026,0.025$, and $0.018 \mathrm{eV}$ at frequencies $5,10,20,50,100$, and $1000 \mathrm{kHz}$, respectively. From the table, one can conclude that the value of activation energy decreases with increase in frequency. This type of behaviour suggests that the conduction mechanism may be due to the hopping of the charge carriers. The polarisation process in $\mathrm{CePO}_{4}$ nanoparticles explained as a local displacement of electrons (i.e., $n$ or $p$ type) by the hopping mechanism between $\mathrm{Ce}^{3+} / \mathrm{Ce}^{4+}$ and an orientation of electric dipoles in the direction of the applied field from one site to another. Therefore, a very small amount of energy is required to activate the charge carriers/electrons for electrical conduction. It has been shown by Ang et al. [37] and Moretti and Michel-Calendini [38] that the value of activation energy depends on ionization level of the oxygen vacancy. Usually, activation energy less than $1.0 \mathrm{eV}$ is connected to singly ionized vacancies [37] and/or electronic mobility in space charge region. Thus, the conduction process within this temperature range may be due to the hopping of charge carriers and/or singly oxygen vacancies.

\section{Conclusions}

In summary, cerium orthophosphate $\left(\mathrm{CePO}_{4}\right)$ nanoparticles having monoclinic monazite phase were prepared by coprecipitation method. From XRD results, the crystallite size comes out to be $49.3 \mathrm{~nm}$ and from particle size analyser one can confirm that the particles grown in the nanoscale range. Transmission and scanning electron microscopic analysis reveals that the particles prepared by this technique are nanosphere having grain size in the range of 30-50 nm which is comparable to the crystallite size. Thermogravimetric and differential thermal analysis (TGA/DTA) suggests that the structural transition from hexagonal to monoclinic phase is taking place above $800^{\circ} \mathrm{C}$. Optical studies using UV-VIS-NIR absorption spectrophotometer shows the maximum absorption in the ultraviolet region and the optical band gap energy of the material was found to be $1.07 \mathrm{eV}$ for direct transition. The photoluminescence spectrum gives strong ultraviolet band at $400 \mathrm{~nm}$ which is caused by the $5 \mathrm{~d}-4 \mathrm{f}$ emission. The electrical properties of these nanospheres show dependence of dielectric constant on both temperature and frequency. The variation of dielectric constant with temperature shows the transition peak shift towards higher temperature as the frequency increases. Therefore, it is suggested to have relaxor ferroelectric behaviour. From the ac conductivity behaviour, the value of activation energy decreases with increase in frequency, suggesting that conduction mechanism is due to the hopping of the charge carriers from one site to another.

\section{Conflict of Interests}

The authors declare that there is no conflict of interests regarding the publication of this paper.

\section{Acknowledgments}

The authors express their gratitude to Sophisticated Test and Instrumentation Centre (STIC) Cochin University for providing the facilities of SEM-EDAX and UV-VIS-NIR spectrophotometer. The authors would also like to acknowledge Professor H. N. Sheikh, Department of Chemistry, University of Jammu, for providing the facility of Zetasizer Nano ZS particle size analyzer and Institute Instrumentation Centre, Indian Institute of Technology, Roorkee, for providing the facility of transmission electron microscopy (TEM).

\section{References}

[1] H. Li, S. Zhang, S. Zhou, and X. Cao, "Bonding characteristics, thermal expansibility, and compressibility of $\mathrm{RXO}_{4}(\mathrm{R}=$ Rare Earths, $\mathrm{X}=\mathrm{P}$, As) within monazite and zircon structures," Inorganic Chemistry, vol. 48, no. 10, pp. 4542-4548, 2009.

[2] A. Meldrum, L. A. Boatner, and R. C. Ewing, "Displacive radiation effects in the monazite- and zircon-structure orthophosphates," Physical Review B: Condensed Matter and Materials Physics, vol. 56, no. 21, pp. 13805-13814, 1997.

[3] R. Kijkowska, E. Cholewka, and B. Duszak, "X-ray diffraction and Ir-absorption characteristics of lanthanide orthophosphates obtained by crystallisation from phosphoric acid solution," Journal of Materials Science, vol. 38, no. 2, pp. 223-228, 2003.

[4] H. Onoda, H. Nariai, H. Maki, and I. Motooka, "Syntheses of various rare earth phosphates from some rare earth compounds," Materials Chemistry and Physics, vol. 73, no. 1, pp. 1923, 2002.

[5] K. Rajesh, P. Mukundan, P. K. Pillai, V. R. Nair, and K. G. K. Warrier, "High-surface-area nanocrystalline cerium phosphate through aqueous sol-gel route," Chemistry of Materials, vol. 16, no. 14, pp. 2700-2705, 2004.

[6] L. Qian, W. Du, Q. Gong, and X. Qian, “Controlled synthesis of light rare earth phosphate nanowires via a simple solution route," Materials Chemistry and Physics, vol. 114, no. 1, pp. 479484, 2009.

[7] N. Ekthammathat, T. Thongtem, A. Phuruangrat, and S. Thongtem, "Facile hydrothermal synthesis and optical properties of monoclinic $\mathrm{CePO}_{4}$ nanowires with high aspect ratio," Journal of Nanomaterials, vol. 2012, Article ID 958593, 6 pages, 2012.

[8] M. Yang, H. You, Y. Zheng et al., "Hydrothermal synthesis and luminescent properties of novel ordered sphere $\mathrm{CePO}_{4}$ hierarchical architectures," Inorganic Chemistry, vol. 48, no. 24, pp. 11559-11565, 2009.

[9] L. Meng, L. Yang, B. Zheu, and C. Cai, "Cerium phosphate nanotubes: synthesis, characterization and biosensing," Nanotechnology, vol. 20, no. 3, Article ID 035502, 2009. 
[10] J. Bao, R. Yu, J. Zhang et al., "Low-temperature hydrothermal synthesis and structure control of nano-sized $\mathrm{CePO}_{4}$," CrystEngComm, vol. 11, no. 8, pp. 1630-1634, 2009.

[11] H. Lai, A. Bao, Y. Yang et al., "UV luminescence property of $\mathrm{YPO}_{4}: \mathrm{RE}\left(\mathrm{RE}=\mathrm{Ce}^{3}+, \mathrm{Tb}^{3+}\right)$," Journal of Physical Chemistry $C$, vol. 112, no. 1, pp. 282-286, 2008.

[12] K. Riwotzki, H. Meyssamy, A. Kornowski, and M. Haase, "Liquid-phase synthesis of doped nanoparticles: colloids of luminescing $\mathrm{LaPO}_{4}$ :Eu and $\mathrm{CePO}_{4}$ :Tb particles with a narrow particle size distribution," The Journal of Physical Chemistry $B$, vol. 104, no. 13, pp. 2824-2828, 2000.

[13] Y. Zhang and H. Guan, "Hydrothermal synthesis and characterization of hexagonal and monoclinic $\mathrm{CePO}_{4}$ single-crystal nanowires," Journal of Crystal Growth, vol. 256, no. 1-2, pp. 156161, 2003.

[14] H. Onoda, H. Nariai, A. Moriwaki, H. Maki, and I. Motooka, "Formation and catalytic characterization of various rare earth phosphates," Journal of Materials Chemistry, vol. 12, no. 6, pp. 1754-1760, 2002.

[15] C. Feldmann and H.-O. Jungk, "Preparation of sub-micrometer $\mathrm{LnPO}_{4}$ particles $(\mathrm{Ln}=\mathrm{La}, \mathrm{Ce})$," Journal of Materials Science, vol. 37, no. 15, pp. 3251-3254, 2002.

[16] J. R. Van Wazer, Phosphorous and Its CPDS, Vol. I and II, Interscience, New York, NY, USA, 1961.

[17] Y. P. Fang, A. W. Xu, R. Q. Song et al., "Systematic synthesis and characterization of single-crystal lanthanide orthophosphate nanowires," Journal of the American Chemical Society, vol. 125, no. 51, pp. 16025-16034, 2003.

[18] Y. Fujishiro, H. Ito, T. Sato, and A. Okuwaki, "Synthesis of monodispersed LaPO4 particles using the hydrothermal reaction of an $\mathrm{La}($ edta) - chelate precursor and phosphate ions," Journal of Alloys and Compounds, vol. 252, no. 1-2, pp. 103-109, 1997.

[19] M. Ocaña, R. Rodriguez-Clemente, and C. J. Serna, "Uniform colloidal particles in solution: formation mechanisms," Advanced Materials, vol. 7, no. 2, pp. 212-216, 1995.

[20] V. Privman, D. V. Goia, J. Park, and E. Matijević, "Mechanism of formation of monodispersed colloids by aggregation of nanosize precursors," Journal of Colloid and Interface Science, vol. 213, no. 1, pp. 36-45, 1999.

[21] S. Lucas, E. Champion, D. Bernache-Assollant, and G. Leroy, "Rare earth phosphate powders $\mathrm{RePO}_{4} \cdot \mathrm{nH}_{2} \mathrm{O}(\mathrm{Re}=\mathrm{La}, \mathrm{Ce}$ or Y) II. Thermal behavior," Journal of Solid State Chemistry, vol. 177, no. 4-5, pp. 1312-1320, 2004.

[22] A. Hezel and S. D. Ross, "Forbidden transitions in the infrared spectra of tetrahedral anions-III. Spectra-structure correlations in perchlorates, sulphates and phosphates of the formula MXO ${ }_{4}$, Spectrochimica Acta, vol. 22, no. 11, pp. 1949-1961, 1966.

[23] F. Zhang and S. S. Wong, "Ambient large-scale templatemediated synthesis of high-aspect ratio single-crystalline, chemically doped rare-earth phosphate nanowires for bioimaging," ACS Nano, vol. 4, no. 1, pp. 99-112, 2010.

[24] J. Tauc, Amorphous and Liquid Semiconductors, Plenum, New York, NY, USA, 1974, edited by J. Tauc.

[25] P. Xu, R. Yu, L. Zong et al., "Phase evolution and photoluminescence enhancement of $\mathrm{CePO}_{4}$ nanowires from a low phosphate concentration system," Journal of Nanoparticle Research, vol. 15, no. 5, article 1622, 2013.

[26] S. Kamba, J. Kulda, V. Petrícek, G. McIntyre, and J. P. Kiat, "High-pressure structural and dielectric studies of the phase transitions in lithium thallium tartrate monohydrate," Journal of Physics: Condensed Matter, vol. 14, no. 15, pp. 4045-4049, 2002.
[27] G. Goodman, R. C. Buchanan, T. G. Reynolds III, and R. C. Buchanan, Eds., Ceramic Materials for Electronics: Processing Properties and Applications, Marcel Dekker, New York, NY, USA, 1991.

[28] K. Prasad, "Diffuse phase transition in perovskite ferroelectrics," Indian Journal of Engineering and Materials Sciences, vol. 7, no. 5-6, pp. 446-450, 2000.

[29] G. Schmidt, "Diffuse phase transition," Ferroelectrics, vol. 78, no. 1, pp. 199-206, 1988.

[30] I. M. Afandiyeva, I. Dökme, Ş. Altindal, M. M. Bülbül, and A. Tataroǧlu, "Frequency and voltage effects on the dielectric properties and electrical conductivity of $\mathrm{Al}-\mathrm{TiW}-\mathrm{Pd}_{2} \mathrm{Si} / \mathrm{n}-\mathrm{Si}$ structures," Microelectronic Engineering, vol. 85, no. 2, pp. 247252, 2008.

[31] J. C. Maxwell, Electricity and Magnetism, vol. 1, Oxford University Press, London, UK, 1873.

[32] A. Dutta and T. P. Sinha, "Structural and dielectric properties of $\mathrm{A}\left(\mathrm{Fe}_{1 / 2} \mathrm{Ta}_{1 / 2}\right) \mathrm{O}_{3}[\mathrm{~A}=\mathrm{Ba}, \mathrm{Sr}, \mathrm{Ca}]$," Materials Research Bulletin, vol. 46, no. 4, pp. 518-524, 2011.

[33] R. N. P. Choudhary and B. K. Choudhary, "Structural and dielectric studies of $\mathrm{GdAsO}_{4}$," Journal of Materials Science Letters, vol. 9, no. 4, pp. 394-396, 1990.

[34] V. Hangloo, R. Tickoo, K. K. Bamzai, and P. N. Kotru, "Dielectric characteristics of mixed Gd-Ba molybdate crystals grown at ambient temperatures by the gel encapsulation technique," Materials Chemistry and Physics, vol. 81, no. 1, pp. 152-159, 2003.

[35] S. Pandita, R. Tickoo, K. K. Bamzai, and P. N. Kotru, "Dielectric characteristics of gel grown mixed rare earth (didymium) heptamolybdate crystals," Materials Science and Engineering B, vol. 87, no. 2, pp. 122-129, 2001.

[36] S. R. Elliot, "A.c. conduction in amorphous chalcogenide and pnictide semiconductors," Advances in Physics, vol. 36, no. 2, pp. 135-218, 1987.

[37] C. Ang, Z. Yu, and L. E. Cross, "Oxygen-vacancy-related lowfrequency dielectric relaxation and electrical conduction in Bi:SrTiO ," Physical Review B, vol. 62, no. 1, pp. 228-236, 2000.

[38] P. Moretti and F. M. Michel-Calendini, "Impurity energy levels and stability of $\mathrm{CR}$ and $\mathrm{MN}$ ions in cubic batio ${ }_{3}$," Physical Review B, vol. 36, no. 7, pp. 3522-3527, 1987. 

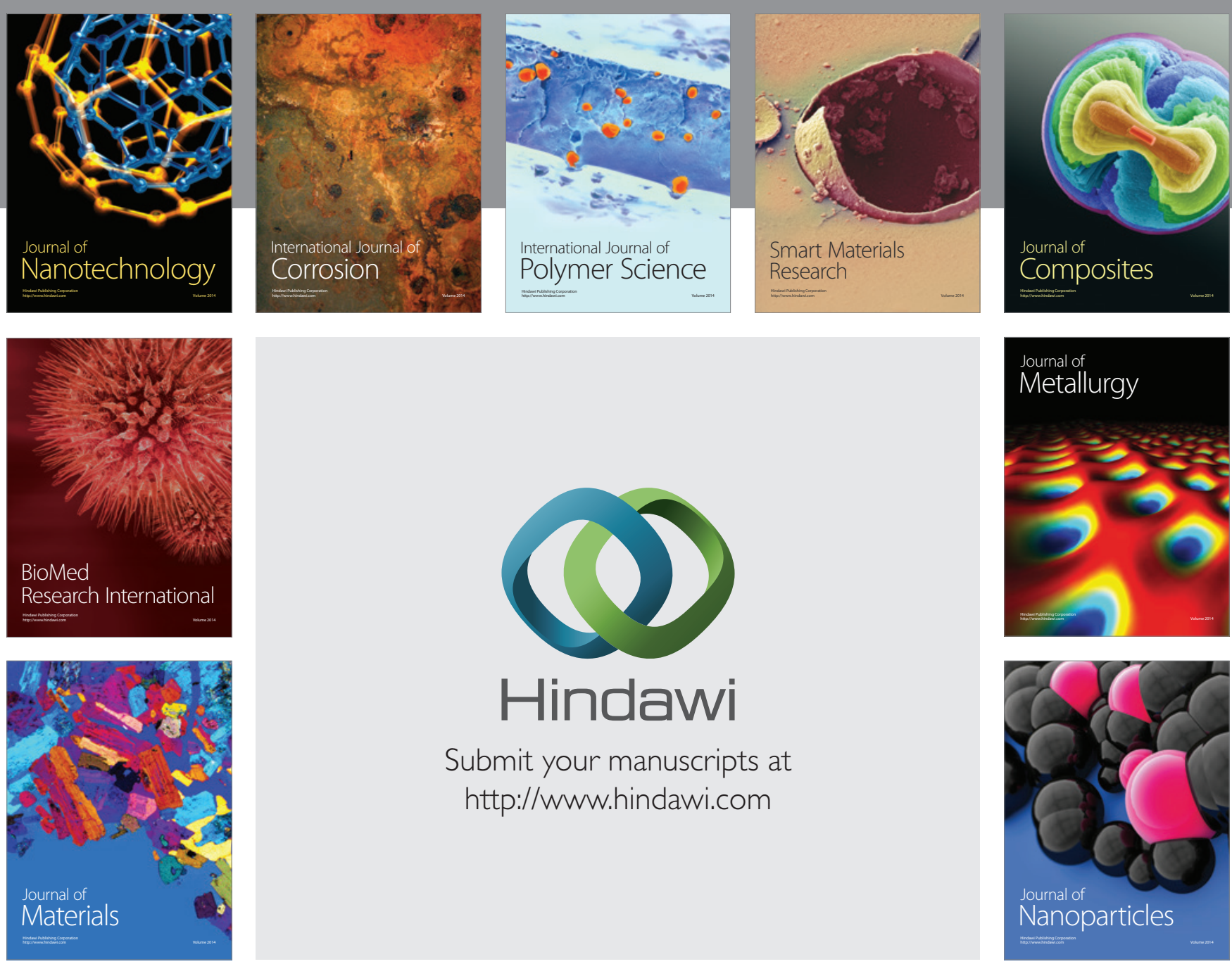

Submit your manuscripts at http://www.hindawi.com
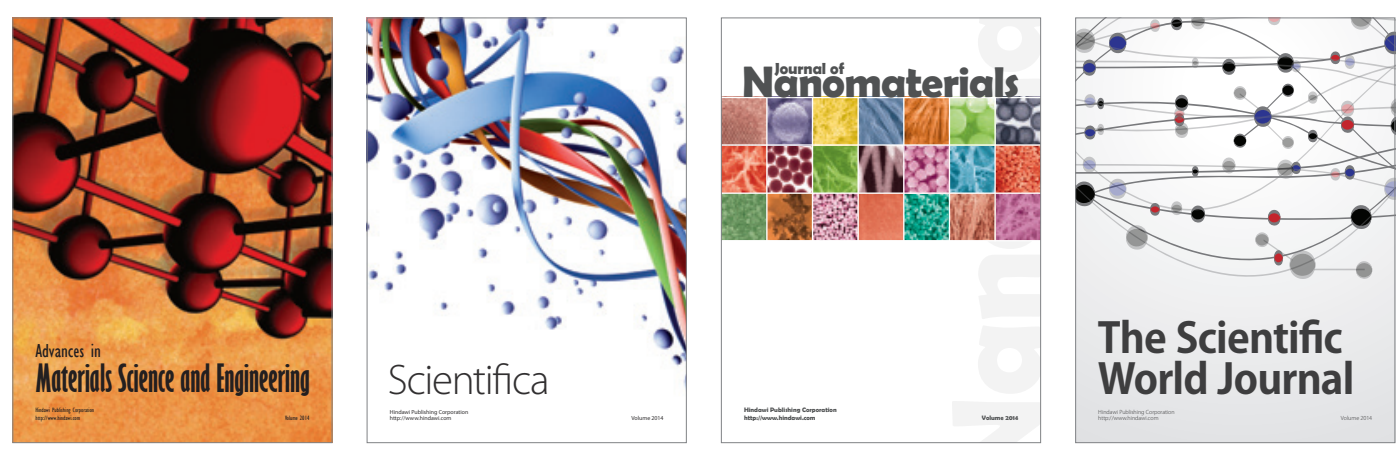

\section{The Scientific World Journal}
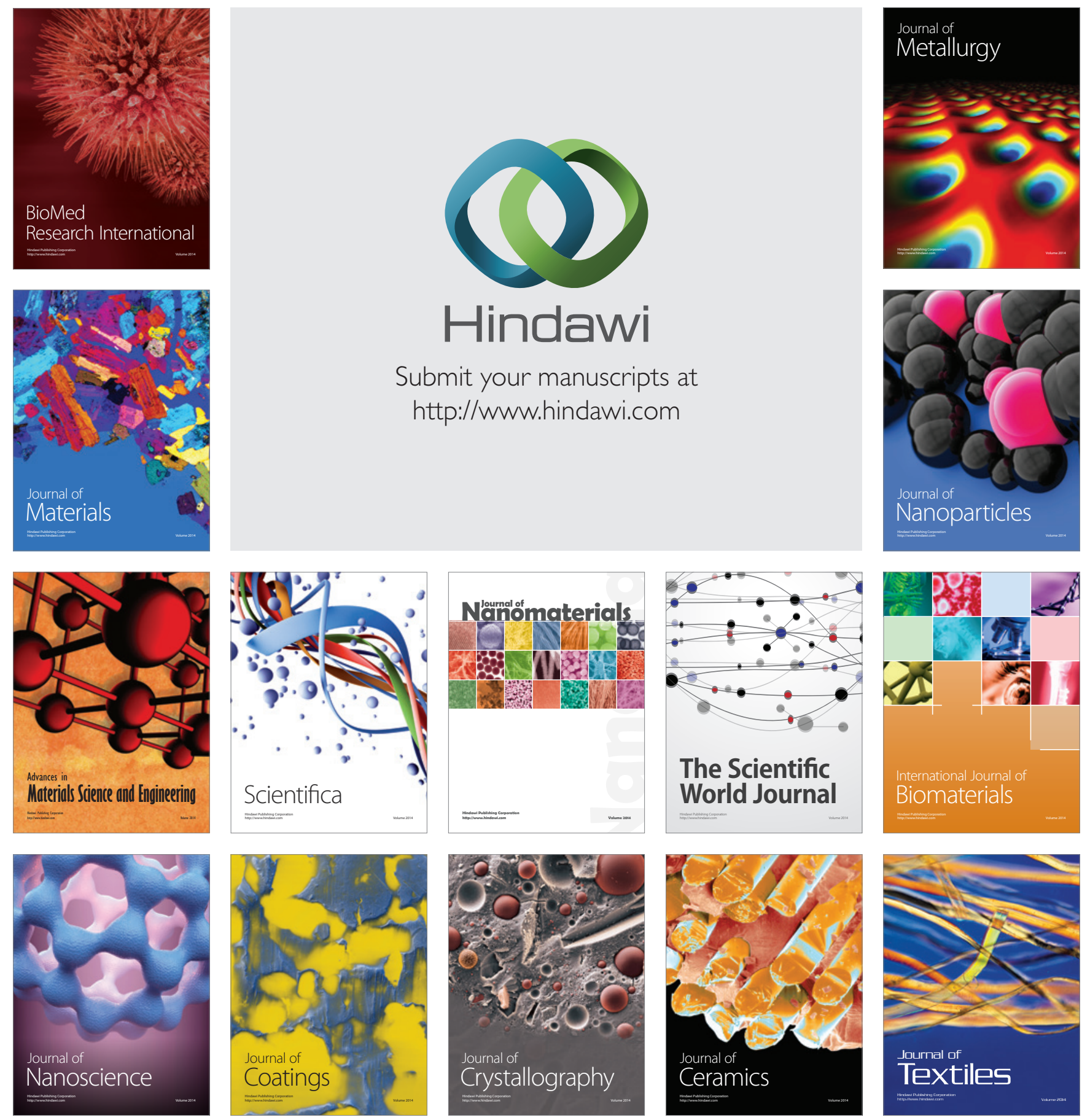